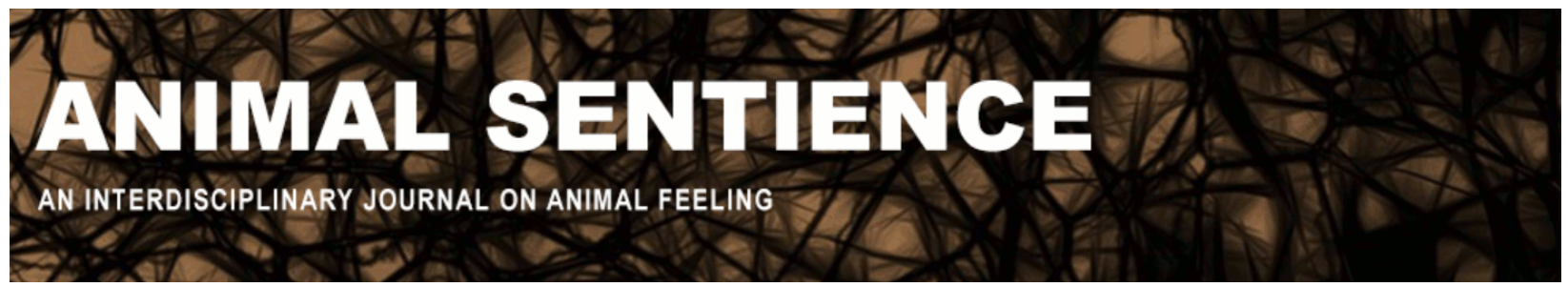

Hall, Geoffrey (2017) Experiment versus analogy in the search for animal sentience. Animal Sentience 12(7)

DOI: $10.51291 / 2377-7478.1257$

Date of submission: 2017-11-17

Date of acceptance: 2017-11-26

(c)

This article has appeared in the journal Animal

Sentience, a peer-reviewed journal on animal

cognition and feeling. It has been made open access,

free for all, by WellBeing International and deposited

in the WBI Studies Repository. For more information,

please contact

wbisr-info@wellbeingintl.org.

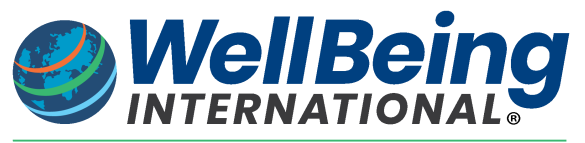

SOLUTIONS FOR PEOPLE, ANIMALS AND ENVIRONMENT 


\title{
Experiment versus analogy in the search for animal sentience
}

\author{
Commentary on Zentall on Cognitive Dissonance
}

\author{
Geoffrey Hall \\ Department of Psychology \\ University of York
}

\begin{abstract}
Deciding between rival accounts of an instance of an animal's behavior can frequently be achieved by experimental tests of different predictions made by the alternatives. When, however, one (or both) of the alternatives is expressed in terms of the mental state of the animal, an experimental test to distinguish them can be hard to find. Although it is unsatisfactory in many ways, it may be necessary to fall back on argument from analogy with human behavior and experience.
\end{abstract}

Geoffrey Hall is Emeritus Professor at the University of York, UK, and Visiting Professorial Fellow at the University of New South Wales, Australia. He has served as Editor of the Quarterly Journal of Experimental Psychology, and of Learning \& Behavior. His primary research interest is in the interaction of perceptual and associative mechanisms in animal learning. www.york.ac.uk/psychology/staff/emeritusfaculty/gh1/

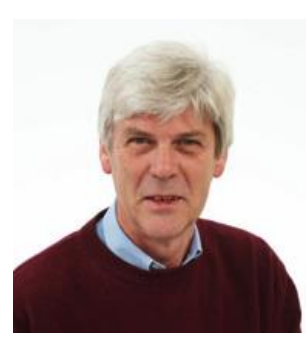

Zentall's (2016) original article, and those who have commented on it already, raise a number of interesting and important issues; but, at the risk of oversimplification, it may be useful to put many of these on one side for the time being, and focus on the following. At the heart of the discussion is a behavioral phenomenon (referred to as the within-trial contrast effect or as a justification-of-effort effect - unfortunately, there is no neutral, atheoretical, label for this effect), and two possible theoretical explanations of the phenomenon: within-trial contrast, and cognitive dissonance. Analysis of the status of these, seemingly alternative, explanations could be informative about the central issue. This issue I take to be: given the context provided by this journal, the extent to which this phenomenon tells us about "the capacity of nonhuman animals to feel" - specifically, to experience the mental states associated with holding conflicting items of knowledge, and the ability to undergo an appropriate attitude change with respect to one of them.

The behavioral phenomenon is clear and well-established. A nonhuman animal (usually a pigeon in the relevant studies) is allowed to choose between two apparently equivalent rewards. These differ only in that, in the past, one has previously been earned after a lot of work; the other, after only a little work. Nonetheless, the pigeon shows a preference for the former. The parallel with certain phenomena observed with human animals is direct. To take a classic example (from Aronson \& Mills, 1959): young women given a hard time before being allowed to join a discussion group rated the activities of the group more positively than others who were allowed to join without trouble. Although apparently equivalent phenomena in different species might well be 
produced by quite different mechanisms (a point well-made by Vonk, 2017), the parallel is close enough to encourage us to attempt to look for a common mechanism. One strategy would be to demonstrate that the effect seen in pigeons is the result of Zentall's contrast effect and then to go on to try to show that this same mechanism is in fact the source of some or all of the phenomena in humans that have been attributed to cognitive dissonance. Another route would be to show that the cognitive dissonance process, rather than Zentall's contrast, is in fact responsible for the effects obtained with pigeons. Either way, a good first step would be to assess the evidence that might allow us to choose between the rival accounts of the phenomenon observed with pigeons in the laboratory.

Having described the basic effect, Zentall cites a number of experimental tests of the theoretical explanation he offers. It is proposed that the value of an event (a stimulus signaling a reward) will be enhanced by the contrast with the negative state produced when a good deal of effort is required to obtain it. This account leads to the prediction that experiencing any relatively negative event (not just effort) should increase the value of the reward that follows. Zentall then cites a substantial set of studies that demonstrate the generality of the contrast effect - the reward is more valued when it is preceded by a delay, by the state of frustration produced by the omission of expected food, by the state of hunger experienced by the animal, and so on. The consistency and reliability of the effects discussed is impressive. What remains an issue, however, is whether they allow a choice between the alternative accounts. The effects studied are derived from the contrast account; but they may be readily accommodated by the dissonance account. It is surely possible to argue in each case that the animal is doing the mental work necessary to resolve the dissonance created by the fact that arriving at the (not very big) reward required a rather unpleasant journey. At this point, one begins to wonder whether these are really clearcut alternative theories that can be separated by experimental tests. Is "dissonance" better regarded as a term for the mental state experienced by animals (including people) under the control of Zentall's contrast mechanism? If so, then a different sort of evidence might be required to resolve the issue.

Reasons to pursue this interpretation come from the study by Klein, Bhatt, and Zentall (2005). In this experiment, adult human participants were trained with a procedure that exactly paralleled the one used with pigeons to investigate justification of effort. That the experiment generated the same outcome with people as with pigeons is consistent with the possibility that contrast is responsible for both species (or that cognitive dissonance is). Significantly, in addition to the standard behavioral data (button presses, etc.), Klein et al. give us the results of introspective reports which reveal that the participants were not aware of the relation between amount of effort and the stimulus it was correlated with. To the extent that the processes responsible for dissonance reduction are assumed to operate at a level open to introspective report, this observation may be taken to indicate that the behavioral results are generated by some other mechanism (such as contrast). Yet however satisfactory it may seem initially, this conclusion has some gloomy implications. For relying on introspective report not only restricts the range of subjects available to study, it also requires us to use a very untrustworthy tool in conducting our studies. There is no need to belabor the point: the evidence and arguments showing that we are all too often mistaken or unaware of the processes responsible for our behavior are overwhelming (see, e.g., Shanks \& St. John, 1994). 
In her analysis of the question of animal consciousness, Heyes (2008) allows two empirical approaches. One, and the one that she advocates, involves the experimental evaluation of rival hypotheses. Specifically, we should use "experimental methods to test against one another two or more alternative explanations for a focal behaviour, B. One of these hypotheses suggests that the behaviour is mediated by phenomenally conscious states or processes, similar to those that mediate the behaviour in humans, whereas the other suggests that B is mediated by alternative, nonconscious states and processes" (Heyes, 2008, p. 261). What I have argued is that the attempt to use this method to resolve alternative interpretations of experiments on justification of effort has failed to come up with the goods. We cannot find experimental evidence that distinguishes between the rival accounts. Perhaps we need to turn to Heyes's other (and less preferred) strategy.

Heyes calls this alternative "analogical reasoning," which she considers the one usually applied to spontaneously occurring behavior. I see no reason in principle it should not apply when the behavior is elicited by an experimental procedure. The name is new but the notion has long been known. It is hardly possible to improve on the description offered over a century ago by its first systematic exponent:

... if we contemplate our own mind, we have an immediate cognizance of a certain flow of thoughts and feelings.... But if we contemplate mind in other persons or organisms, we have no such immediate cognizance.... In such cases we can only infer the existence and nature of thoughts and feelings from the activities of the organisms.... Hence it is evident that in our study of animal intelligence we are wholly restricted to the objective method. Starting from what I know of my own individual mind, and the activities which in my own organism they prompt, I proceed by analogy to infer from the observable activities of other organisms what are the mental operations that underlie them. (Romanes, 1882, pp. 1-2)

\section{References}

Aronson, E., \& Mills, J. (1959). The effect of severity of initiation on liking for a group. Journal of Abnormal and Social Psychology, 59, 177-181.

Heyes, C. (2008). Beast machines? Questions of animal consciousness. In Weiskrantz, L. \& Davies, M. (Eds.), Frontiers of consciousness: Chichele lectures (pp. 259-274). Oxford: Oxford University Press.

Klein, E.D., Bhatt, R.S., \& Zentall, T.R. (2005). Contrast and the justification of effort.

Psychonomic Bulletin \& Review, 12, 335-339.

Romanes, G.J. (1882). Animal intelligence. London: Kegan Paul, Trench, \& Co.

Shanks, D.R., \& St. John, M.F. (1994). Characteristics of dissociable human learning systems.

Behavioral and Brain Sciences, 17, 367-447.

Vonk, J. (2017). What can research on nonhumans tell us about human dissonance? Animal

Sentience 12(2).

Zentall, T.R. (2016). Cognitive dissonance or contrast? Animal Sentience 12(1). 